\title{
Bilateral internal thoracic artery grafting: Does graft configuration affect outcome?
}

J. Trent Magruder, MD, Allen Young, BA, Joshua C. Grimm, MD, John V. Conte, MD, Ashish S. Shah, MD, Kaushik Mandal, MD, Christopher M. Sciortino, MD, PhD, Kenton J. Zehr, MD, Duke E. Cameron, MD, and Joel Price, MD, MPH

\begin{abstract}
Background: Despite evidence that bilateral internal thoracic arteries (ITAs) improve long-term survival after coronary artery bypass grafting (CABG), uptake of this technique remains low. We directly compared bilateral ITA graft configurations and examined long-term outcomes.
\end{abstract}

Methods: We reviewed 762 patients who underwent CABG using bilateral ITA grafts at our institution between 1997 and 2014. The outcomes were mortality and a composite revascularization end point defined as need for percutaneous coronary intervention or repeat CABG. Adjusted subgroup analyses were performed using propensity score-adjusted Cox proportional hazards modeling.

Results: The cohort was divided into 4 groups: in situ (left ITA [LITA] anastomosed to the left anterior descending artery [LAD] with in situ right ITA [RITA] anastomosed to the left coronary circulation [239 patients]); in situ LITA-LAD and in situ RITA-right coronary circulation (239 patients); in situ RITA-LAD with in situ LITA-left coronary circulation (185 patients); and in situ LITA-LAD with a free RITA as a composite graft with inflow from the LITA or a saphenous vein graft (99 patients). Over a median follow-up of 1128 days, there were 47 deaths, 58 late percutaneous coronary interventions, and 7 repeat $C A B G$ procedures. Unadjusted Kaplan-Meier analysis revealed a difference in need for repeat revascularization among the 4 groups (log rank $P=.049$ ). However, after statistical adjustment, graft configuration was not an independent predictor of repeat revascularization or death.

Conclusions: Bilateral ITA graft configuration has no independent effect on need for repeat revascularization or long-term survival. Therefore, the simplest technique, determined by individual patient characteristics, should be selected. (J Thorac Cardiovasc Surg 2016;152:120-7)

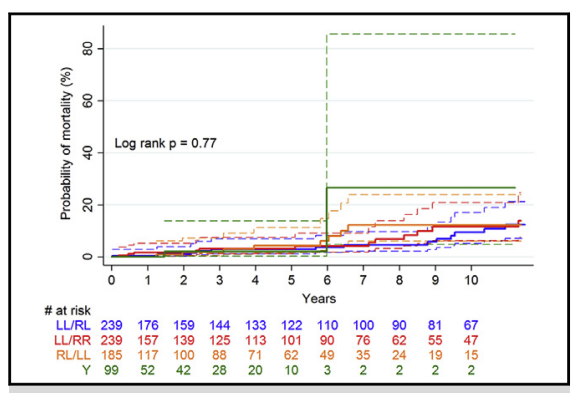

Unadjusted time-to-event curves showing risk of repeat revascularization and/or mortality in patients with a left internal thoracic artery-left anterior descending artery versus right internal thoracic artery-left anterior descending artery anastomosis.

\section{Central Message}

There is no advantage to any particular configuration of bilateral internal thoracic artery graft in terms of mortality or the need for repeat revascularization.

\section{Perspective}

Despite evidence that bilateral internal thoracic arteries improve long-term survival after coronary artery bypass grafting, uptake of this technique remains low. We analyzed 4 different graft configurations with respect to outcomes. We found no adjusted differences in the need for repeat revascularization or death among the configurations.

See Editorial Commentary page 128.
Evidence continues to accumulate that the use of bilateral internal thoracic arteries (BITA) in coronary artery bypass grafting (CABG) positively affects long-term survival. It has been very well established that anastomosing the left

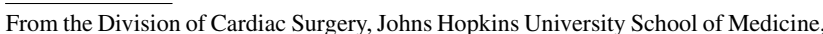
Baltimore, Md.

Received for publication Sept 25, 2015; revisions received Feb 8, 2016; accepted for publication March 1, 2016.

Address for reprints: Joel Price, MD, MPH, Division of Cardiac Surgery, Johns Hopkins University School of Medicine, 1800 Orleans St, Zayed 7107, Baltimore, MD 21287 (E-mail: jprice@jhmi.edu). 0022-5223/\$36.00

Copyright $₫ 2016$ Published by Elsevier Inc. on behalf of The American Association for Thoracic Surgery

http://dx.doi.org/10.1016/j.jtcvs.2016.03.022 internal thoracic artery (LITA) to the left anterior descending artery (LAD) improves graft patency and overall survival. ${ }^{1-3}$ Several authors have documented improved long-term survival with BITA as opposed to single internal thoracic artery (ITA) use in large cohorts undergoing $\mathrm{CABG}^{4-6}$ A number of other groups have found that BITA use improves survival in specific subgroups. ${ }^{7-12}$ Other authors contend

Scanning this QR code will take you to the article title page. 


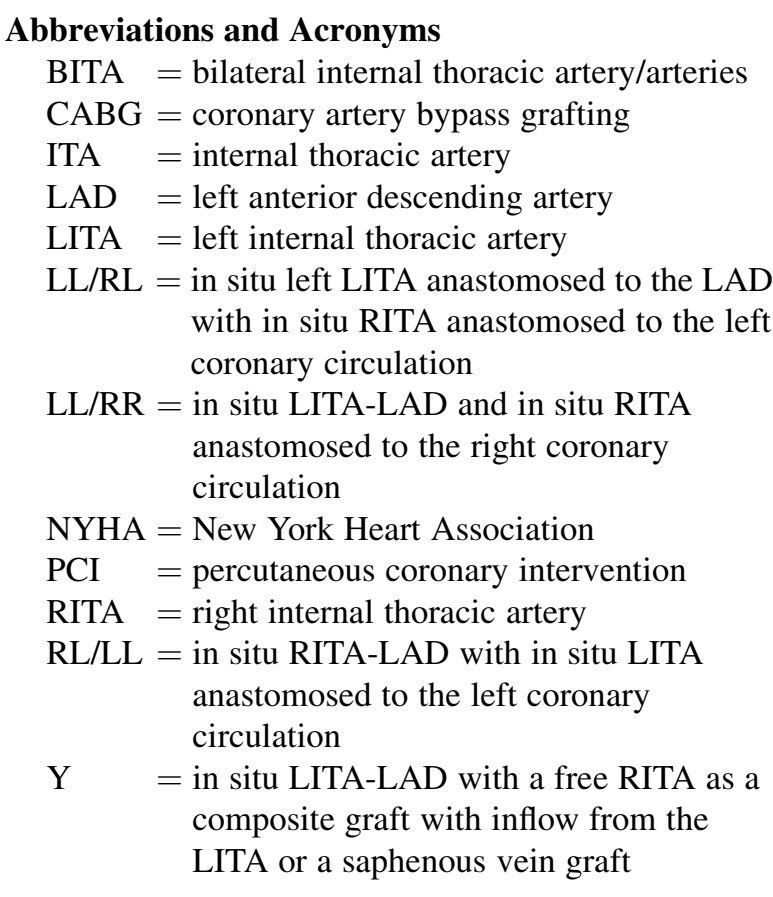

that the survival advantage of BITA use appears only over decades and exclusively in younger patients. ${ }^{6,13}$

Despite the evidence of benefit, BITA use in the United States remains relatively low. A contemporary survey of American cardiac surgeons reported BITA use in $4 \%$ of CABG procedures. ${ }^{14}$ Slightly higher uptake of $12 \%$ has been reported in Europe. ${ }^{15}$ There are a number of possible explanations for the modest uptake of this technique. Some note discrepant data suggesting BITA use is not associated with an overall survival advantage in many patients. ${ }^{16-19}$ Another key concern is that BITA use may increase the incidence of sternal surgical site infections, particularly in subgroups that include diabetic patients, obese patients, and those with chronic obstructive pulomonary disease. ${ }^{18,20,21}$ Finally, the harvesting and use of BITA increases the time and technical complexity of the operation and increases the potential for bleeding.

Given the paucity of comparative data on long-term outcomes of various BITA configurations, we sought to study differences in mortality and the need for repeat revascularization among patients receiving varying BITA graft configurations at our institution. Our hypothesis was that graft configuration does not affect these outcomes.

\section{METHODS}

\section{Patient Population and Operative Details}

Of 14,502 isolated CABG operations performed at our institution between 1997 and 2014, we performed a review of 822 patients who had CABG using bilateral ITA grafts (BITA use rate, 5.7\%). Of these, 606 $(73.7 \%)$ underwent LITA to LAD anastomoses (LITA-LAD), whereas $203(24.7 \%)$ underwent right internal thoracic artery (RITA)-LAD anastomoses (RITA-LAD); the remainder had incomplete operative records. BITA patients were divided into 4 groups based on graft configuration: patients who had in situ LITA-LAD and in situ RITA anastomosed to the left coronary circulation (group LL/RL, $\mathrm{n}=239$; $31.4 \%$ ); patients who had in situ LITA-LAD and in situ RITA anastomosed to the right coronary circulation (group LL/RR, $n=239 ; 31.4 \%$ ); patients who had in situ RITA-LAD and in situ LITA anastomosed to the left coronary circulation (group RL/LL, $\mathrm{n}=185 ; 24.3 \%$ ); and patients who had in situ LITA-LAD and the RITA harvested as a free graft and anastomosed proximally as a composite graft from the LITA or a saphenous vein graft, and anastomosed distally to any part of the coronary circulation (group composite [Y], $\mathrm{n}=99 ; 12.9 \%$ ). A total of 762 patients were included in our study. Patients with unclear or missing operative records were excluded (60 patients; $7.3 \%$ ).

Multiple surgeons were included in this series and conduit selection and configuration was always determined by the operating surgeon. In general, we have avoided BITA harvesting in patients who are obese, have diabetes, and/or have a history of pulmonary disease. Generally, BITA procedure was employed in younger, healthier patients with good life expectancy and at low risk of sternal complications. Our standard strategy was to direct ITAs to diseased coronary arteries serving the largest portions of myocardium. Techniques varied between surgeons but all CABG procedures were performed on cardiopulmonary bypass using cardioplegic arrest. The LITA was always harvested as a pedicled graft. In more recent years (predominantly since 2007), a significant proportion of RITA grafts have been harvested as skeletonized conduits ( 205 of 617 total RITA grafts; $33.2 \%)$.

\section{Study Design}

After obtaining appropriate institutional review board approval, we retrospectively examined patient charts to determine patient characteristics and demographic characteristics, operative details, and postoperative outcomes. Preoperative variables analyzed included age, gender, hypertension, hyperlipidemia, diabetes, ejection fraction, New York Heart Association (NYHA) class, preoperative atrial fibrillation, history of tobacco use, presence of chronic lung disease, presence of peripheral vascular disease, prior cerebrovascular accident, reoperative surgery, and operative status (elective vs urgent vs emergent). Operative variables analyzed included crossclamp and bypass times as well as the need for intraoperative blood products. Analyzed outcomes were mortality, obtained from medical records and confirmed by review of the Social Security Death Index and/or online obituary databases (in which case a mortality was only counted upon matching a patient's full name, date of birth, and hometown), and a composite revascularization end point defined as the need for repeat CABG or percutaneous coronary intervention (PCI) after the index $\mathrm{CABG}$ operation. We also examined the combined need for repeat CABG or PCI, or death, whichever occurred first.

Secondary outcomes included perioperative myocardial infarction, perioperative cerebrovascular accident, mediastinitis, and reoperation for bleeding. Mediastinitis was defined according to the Society of Thoracic Surgeons definition, which requires evidence of mediastinitis observed during a procedure or histopathologically positive mediastinal cultures, or fever, chest pain, or sternal instability; and the patient must have either purulent discharge, positive blood cultures, or mediastinal widening on imaging.

\section{Statistical Analysis}

Statistical analyses were performed using Stata 12 (StataCorp, College Station, Tex). Demographic data are presented as frequencies and percentages. Categorical univariable comparisons were performed using Fisher exact or $\chi^{2}$ tests. Continuous variables were compared using analysis of variance with a Bonferroni correction. Unadjusted survival and time to repeat revascularization were analyzed using Kaplan-Meier methodology and log rank tests. 
TABLE 1. Demographic information of patients $(N=762)$

\begin{tabular}{|c|c|c|c|c|c|}
\hline & LL/RL & LL/RR & RL/LL & $\mathbf{Y}$ & $P$ value \\
\hline $\mathrm{n}$ & 239 & 239 & 185 & 99 & - \\
\hline Median age (y) & $56 \pm 8$ & $58 \pm 10$ & $59 \pm 9$ & $55 \pm 9$ & .001 \\
\hline Male & $216(90.4)$ & $198(82.9)$ & $170(91.9)$ & $90(90.9)$ & .02 \\
\hline Hypertension & $157(65.7)$ & $156(65.3)$ & $145(78.4)$ & $78(78.8)$ & .002 \\
\hline Hyperlipidemia & $189(79.1)$ & 179 (74.9) & $149(80.5)$ & $87(87.9)$ & .05 \\
\hline Diabetes & $30(12.6)$ & $34(14.2)$ & $50(27.0)$ & $36(36.4)$ & $<.001$ \\
\hline Mean EF (\%) & $54.3 \pm 9.6$ & $53.2 \pm 10.3$ & $53.8 \pm 10.1$ & $52.2 \pm 11.5$ & .62 \\
\hline NYHA class III-IV & $31(13.0)$ & $41(17.2)$ & $6(3.2)$ & $2(2.0)$ & $<.001$ \\
\hline Preoperative AF & $5(2.1)$ & $5(2.1)$ & $7(3.8)$ & $2(2.1)$ & .65 \\
\hline Current or prior tobacco use & $123(51.5)$ & $102(42.7)$ & $62(33.5)$ & $14(14.1)$ & $<.001$ \\
\hline COPD & $9(3.8)$ & $16(6.7)$ & $10(5.4)$ & $7(7.1)$ & .44 \\
\hline PVD & $15(6.3)$ & $14(5.9)$ & $21(11.4)$ & $7(7.1)$ & .17 \\
\hline Prior CVA & $7(2.9)$ & $6(2.5)$ & $10(5.4)$ & $5(5.1)$ & .32 \\
\hline Redo CABG & $2(0.8)$ & $4(1.7)$ & $1(0.5)$ & 0 & .60 \\
\hline Urgent or emergent operation & $90(37.7)$ & 99 (41.4) & $73(39.5)$ & $48(48.5)$ & .31 \\
\hline Operation performed after 2006 & $52(21.8)$ & $102(42.7)$ & $121(65.4)$ & $92(92.9)$ & $<.001$ \\
\hline
\end{tabular}

Values are presented as $\mathrm{n}(\%)$ or mean \pm standard deviation. Boldface indicates statistical significance. $L L / R L$, In situ left LITA anastomosed to the LAD with in situ RITA anastomosed to the left coronary circulation; $L L / R R$, in situ LITA-LAD and in situ RITA anastomosed to the right coronary circulation; $R L / L L$, in situ RITA-LAD with in situ LITA anastomosed to the left coronary circulation; $Y$, in situ LITA-LAD with a free RITA as a composite graft with inflow from the LITA or a saphenous vein graft; $E F$, ejection fraction; NYHA, New York Heart Association, $A F$, atrial fibrillation, COPD, chronic obstructive pulmonary disease; $P V D$, peripheral vascular disease; CVA, cerebrovascular accident; $C A B G$, coronary artery bypass grafting.

Given the limitations of the cohort and the 4 groups, adjusted analyses were performed as a number of pairwise subgroup comparisons. Many authors suggest that the right coronary artery territory should not receive an arterial conduit, particular when critical stenosis are not present. ${ }^{22-27}$ As such, the first comparison was between patients who received 2 in situ ITA grafts to the left coronary circulation (the LL/RL vs RL/LL groups). A second adjusted subgroup analysis was performed to examine the outcomes of strategies that employ a LITA to the LAD $(\mathrm{LL} / \mathrm{RL}+\mathrm{LL} / \mathrm{RR}+\mathrm{Y})$ versus those that use an RITA to the LAD (RL). Finally, a third subgroup analysis was conducted comparing patients with a LITA-LAD anastomosis and a RITA anastomosed to the left coronary circulation (either in situ or as a Y-composite graft), versus a LITA-LAD anastomosis and an in situ RITA anastomosed to the right coronary circulation. To control for selection bias in each of these analyses, for each of the 3 above analyses we calculated propensity scores using a nonparsimonious logistic regression model that included the following variables: age, gender, race, hypertension, hyperlipidemia, diabetes, ejection fraction, NYHA class, preoperative atrial fibrillation, tobacco use, chronic lung disease, peripheral vascular disease, history of cerebrovascular accident, reoperative status, urgent or emergent operative status, and operative year. The propensity score was then used as the sole covariate in a Cox proportional-hazards model to determine the influence of graft configuration on the outcome of mortality or need for repeat revascularization. The final model comparing left-sided in situ ITA configurations had a C-statistic 0.81 ; the final model for LITA-LAD versus RITA-LAD anastomosis had a C-statistic 0.76. The final model for the subgroup analysis comparing patients with a LITA-LAD and RITA to left versus RITA right coronary systems had a C-statistic of 0.64 .

\section{RESULTS}

Table 1 shows demographic information for the 4 patient groups. Significant differences were found between groups in patient age, diabetes, NYHA class III or IV status, and smoking history. We also noted a significant difference in the era during which certain graft configurations tended to be performed.

Operative data are shown in Table 2. The frequency of intraoperative blood transfusion and RITA skeletonization differed significantly between groups. Table 3 shows the RITA distal anastomosis sites by cohort. Within each cohort, the predominant distal RITA target was the obtuse

TABLE 2. Operative data

\begin{tabular}{|c|c|c|c|c|c|}
\hline & LL/RL & LL/RR & RL/LL & $\mathbf{Y}$ & $P$ value \\
\hline Mean crossclamp time (min) & $78.8 \pm 28.5$ & $71.7 \pm 28.4$ & $63.6 \pm 24.0$ & $71.7 \pm 30.9$ & .02 \\
\hline Mean CPB time (min) & $107 \pm 35.3$ & $103.4 \pm 36.3$ & $93.1 \pm 32.7$ & $104.6 \pm 38.5$ & .27 \\
\hline Intraoperative transfusion & $59(24.7)$ & $90(37.7)$ & $80(43.2)$ & $57(57.6)$ & $<.001$ \\
\hline LITA in situ anastomosed to LAD & $239(100.0)$ & $239(100.0)$ & $0(0.0)$ & $99(100.0)$ & - \\
\hline RITA skeletonized at harvest & $19(8.0)$ & $43(18.0)$ & $58(31.4)$ & $72(72.7)$ & $<.001$ \\
\hline Number of bypass grafts & $3.2 \pm 0.8$ & $3.1 \pm 0.8$ & $3.0 \pm 0.8$ & $3.4 \pm 0.9$ & .005 \\
\hline Radial artery used as third conduit & $9(3.8)$ & $12(5.0)$ & 0 & $1(1.0)$ & 01 \\
\hline
\end{tabular}

Values are presented as $\mathrm{n}(\%)$ or mean \pm standard deviation. Boldface indicates statistical significance. $L L / R L$, In situ left LITA anastomosed to the LAD with in situ RITA anastomosed to the left coronary circulation; $L L / R R$, in situ LITA-LAD and in situ RITA anastomosed to the right coronary circulation; $R L / L L$, in situ RITA-LAD with in situ LITA anastomosed to the left coronary circulation; $Y$, in situ LITA-LAD with a free RITA as a composite graft with inflow from the LITA or a saphenous vein graft; $C P B$, cardiopulmonary bypass; LITA, left internal thoracic artery; LAD, left anterior descending artery; RITA, right internal thoracic artery. 
TABLE 3. Right internal thoracic artery (RITA) and left internal thoracic artery (LITA) graft distal anastomoses

\begin{tabular}{lrrrr}
\hline & LL/RL & LL/RR & RL/LL & Y \\
\hline RITA distal anastomoses & & & & \\
N & 239 & 239 & 185 & 99 \\
LAD & 0 & 0 & 185 & 0 \\
Circumflex artery & 2 & 0 & 0 & 0 \\
Diagonal artery & 39 & 0 & 0 & 2 \\
Obtuse marginal artery & 169 & 0 & 0 & 82 \\
Posterior descending artery & 0 & 44 & 0 & 2 \\
Posterolateral artery & 0 & 0 & 0 & 1 \\
Right coronary artery & 0 & 195 & 0 & 0 \\
Ramus intermedius & 29 & 0 & 0 & 12 \\
LITA distal anastomoses & & & & \\
LAD & 239 & 239 & 0 & 99 \\
Circumflex artery & 0 & 0 & 1 & 0 \\
Diagonal artery & 0 & 0 & 10 & 0 \\
Obtuse marginal artery & 0 & 0 & 174 & 0 \\
\hline
\end{tabular}

$L L / R L$, In situ left LITA anastomosed to the LAD with in situ RITA anastomosed to the left coronary circulation; $L L / R R$, in situ LITA-LAD and in situ RITA anastomosed to the right coronary circulation; $R L / L L$, in situ RITA-LAD with in situ LITA anastomosed to the left coronary circulation; $Y$, in situ LITA-LAD with a free RITA as a composite graft with inflow from the LITA or a saphenous vein graft; RITA, right internal thoracic artery; $L A D$, left anterior descending artery; LITA, left internal thoracic artery.

marginal artery in the LL/RL group $(70.7 \%)$, the right coronary artery in the LL/RR group $(81.6 \%)$, and the obtuse marginal artery in the $\mathrm{Y}$ group $(82.8 \%)$. Among the RL/LL group, distal anastomosis targets for the in situ LITA were obtuse marginal arteries in 174 patients ( $94.1 \%$ of RL/LL group), diagonal coronary arteries in 10 patients $(5.4 \%)$, and the left circumflex artery in 1 patient $(0.5 \%)$. The mean number of bypass grafts per case was 3.2 in the LL/RL group, 3.1 in the LL/RR group, 3.0 in the $\mathrm{RL} / \mathrm{LL}$ group, and 3.4 in the $\mathrm{Y}$ group $(P=.005)$. Radial artery (as opposed to saphenous vein) was used as the third conduit for bypass grafting in 22 total patients $(2.9 \%$ overall; $3.8 \% \mathrm{LL} / \mathrm{RL}, 5.0 \% \mathrm{LL} / \mathrm{RR}, 0 \mathrm{RL} / \mathrm{LL}$, and $1.0 \%$ $\mathrm{Y} ; \mathrm{P}=.01)$.

In-hospital complications are shown in Table 4. There were 9 reoperations for bleeding, no perioperative myocardial infarctions, and 5 cases of mediastinitis diagnosed during the initial hospital stay (aggregate rate, $0.7 \% ; 2 \mathrm{LL} / \mathrm{RL}$ vs $1 \mathrm{LL} / \mathrm{RR}$ vs $2 \mathrm{RL} / \mathrm{LL}$ vs $0 \mathrm{Y}$; $P=.81)$. Median length of stay differed among the 4 groups (6.1 vs 7.4 vs 7.4 vs 7.0 days; $P<.001$ ).

Median follow-up, which overall was 1128 days, differed significantly between groups (1947 days in LL/RL patients, 1289 days in LL/RR patients, 857 days in RL/LL patients, and 467 days in Y patients; $P<.001$ ). A total of 3593 patient-years of follow-up were analyzed. At 5 years, 291 of the included 762 patients remained at risk $(38.2 \%)$. Across the duration of follow-up, there were 58 repeat PCIs (16 vs 16 vs 17 vs 9) and 6 repeat CABGs (2 vs 4 vs 1 vs 0 ), for a total of 65 repeat revascularizations required.
TABLE 4. In-hospital complications

\begin{tabular}{lccccc}
\hline & LL/RL & LL/RR & RL/LL & Y & $\boldsymbol{P}$ value \\
\hline $\begin{array}{l}\text { Reoperation } \\
\quad \text { for bleeding }\end{array}$ & $3(2.3)$ & $2(0.8)$ & $2(1.1)$ & $2(2.0)$ & .80 \\
MI & 0 & & & & \\
CVA & $4(1.7)$ & $3(1.3)$ & $4(2.2)$ & $3(3.0)$ & .64 \\
Mediastinitis & $2(0.8)$ & $1(0.4)$ & $2(1.1)$ & 0.0 & .81 \\
In-hospital death & $2(0.9)$ & $1(0.4)$ & 0 & 0 & .86 \\
Mean LOS (d) & $\mathbf{6 . 1} \pm \mathbf{3 . 3}$ & $\mathbf{7 . 4} \pm \mathbf{9 . 6}$ & $\mathbf{7 . 4} \pm \mathbf{4 . 6}$ & $\mathbf{7 . 0} \pm \mathbf{3 . 7}$ & $<.001$ \\
\hline
\end{tabular}

All data shown as $\mathrm{n}(\%)$ or mean \pm standard deviation. Boldface indicates statistical significance. $L L / R L$, In situ left LITA anastomosed to the LAD with in situ RITA anastomosed to the left coronary circulation; $L L / R R$, in situ LITA-LAD and in situ RITA anastomosed to the right coronary circulation; $R L / L L$, in situ RITA-LAD with in situ LITA anastomosed to the left coronary circulation; $Y$, in situ LITA-LAD with a free RITA as a composite graft with inflow from the LITA or a saphenous vein graft; $M I$, myocardial infarction; $C V A$, cerebrovascular accident; $L O S$, length of stay.

There were 47 total late deaths ( 18 vs 18 vs 9 vs 2 ). Deaths were cardiac in $12,11,9$, and 0 ; and noncardiac in $6,7,0$, and 2 in each group, respectively. Five-year survival in the 4 groups was $97.1 \%, 96.8 \%, 95.7 \%$, and $97.9 \%$, respectively. Ten-year survival was $90.5 \%, 88.5 \%$, $87.8 \%$, and $73.4 \%$, respectively (log rank $P=.77$ ) (Figure 1, A). Five-year freedom from repeat revascularization was $93.9 \%$ in the LL/RL group, $90.7 \%$ in the LL/RR group, $85.1 \%$ in the RL/LL group, and $87.5 \%$ in the Y group (log rank $P=.049$ ) (Figure $1, B$ ). Five-year freedom from the combined outcome of death or repeat revascularization in the 4 groups was $91.9 \%$, $88.6 \%, 81.7 \%$, and $85.4 \%(\log \operatorname{rank} P=.03)$ (Figure $1, C)$.

In the subgroup analysis comparing patients who received an in situ ITA graft to the LAD as well as a second in situ ITA graft to the left coronary circulation, unadjusted survival at 5 years was $97.1 \%$ and $95.7 \%$ for the LL/RL and RL/LL groups, whereas unadjusted 10-year survival was $90.5 \%$ and $87.8 \%$, respectively (log rank $P=.39$ ). Unadjusted 5-year freedom from repeat revascularization was $93.9 \%$ and $85.1 \%$ in the LL/RL and RL/LL groups, whereas the unadjusted 10-year freedom figures were $86.5 \%$ and $80.5 \%$, respectively ( $\log$ rank $P=.04$ ). Unadjusted 5-year freedom from the composite outcome of death or repeat revascularization was $92.4 \%$ in the LL/RL group and $85.1 \%$ in the RL/LL group; at 10 years it was $80.1 \%$ and $78.4 \%$, respectively ( $\log$ rank $P=.26$ ). On adjusted analysis, no significant differences were seen in the RL/LL group compared with the LL/RL group for the hazards of mortality (hazard ratio [HR], 0.67; 95\% confidence interval $[\mathrm{CI}], 0.26-1.73 ; P=.41$ ), repeat revascularization (HR, $1.16 ; 95 \% \mathrm{CI}, 0.55-2.47 ; P=.69$ ), or the combined endpoint of repeat revascularization or mortality (HR, $1.01 ; 95 \% \mathrm{CI}, 0.55-1.83 ; P=.99)$.

A subgroup analysis was performed comparing all patients with a LITA-LAD anastomosis (478 patients) versus all those with an RITA-LAD anastomosis (185 patients). Unadjusted 5-year survival was $97.0 \%$ in the 

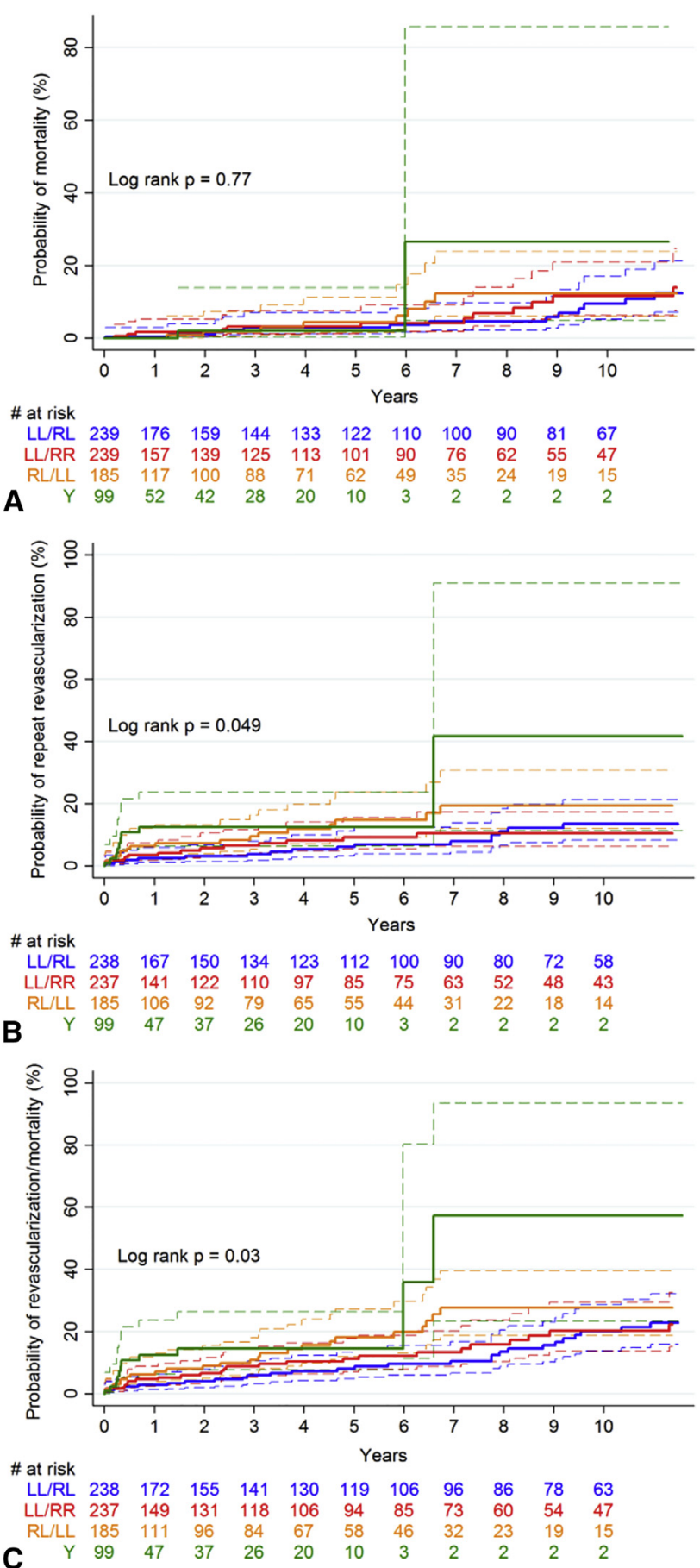

FIGURE 1. Kaplan-Meier curves comparing the 4 groups for the outcomes of (A) Death; (B) Repeat revascularization; and (C) Combined death or repeat revascularization. $L L / R L$, In situ left LITA anastomosed to the LAD with in situ RITA anastomosed to the left coronary circulation; $L L / R R$, in situ LITA-LAD and in situ RITA anastomosed to the right coronary circulation; $R L / L L$, in situ RITA-LAD with in situ LITA anastomosed to the left coronary circulation; $Y$, in situ LITA-LAD with a free RITA as a composite graft with inflow from the LITA or a saphenous vein graft.
LITA-LAD group and $95.7 \%$ in the RITA-LAD group, whereas unadjusted 10 -year survival was $89.7 \%$ and 87.8 , respectively (log-rank $P=.46$ ) (Figure $2, A$ ). Unadjusted 5 -year freedom from repeat revascularization was $92.4 \%$ in the LITA-LAD group and $85.1 \%$ in the RITA-LAD group; at 10 years it was $87.4 \%$ and $80.5 \%$, respectively (log rank $P=.05$ ) (Figure 2, $B$ ). Unadjusted 5-year freedom from the composite outcome of death or repeat revascularization was $90.3 \%$ in the LITA-LAD group and $81.7 \%$ in the RITA-LAD group; at 10 years it was $79.6 \%$ and $72.2 \%$, respectively ( $\log$ rank $P=.04$ ) (Figure 2, $C$ ). On adjusted analysis, a RITA-LAD anastomosis was comparable to a LITA-LAD anastomosis for the hazards of mortality (HR, $0.71 ; 95 \% \mathrm{CI}, 0.31-1.61 ; P=.41$ ), repeat revascularization (HR, 1.18; 95\% CI, 0.64-2.19; $P=.60$ ), and the combined death and repeat revascularization end point (HR, 1.00; 95\% CI, 0.60-1.65; $P=.99$ ).

Finally, in our subgroup analysis of patients with a LITA-LAD anastomosis and a RITA (in situ or Y) anastomosed to the left coronary system (335 patients) versus a RITA to the right coronary system (LL/RR group, 239 patients), we documented no significant differences across any outcome. Of note, in the RITA-left coronary system group, 96 of the 335 patients had a Y-composite graft that was based proximally on the LITA in 71 patients $(74.0 \%)$ and a saphenous vein graft in 25 patients $(26.0 \%)$. Unadjusted 5-year survival was $97.3 \%$ in the RITA-left group and $96.8 \%$ in the RITA-right group; 10 -year survival figures were $90.1 \%$ and $88.5 \%$, respectively (log rank $P=.49$ ). Unadjusted 5-year freedom from repeat revascularization was $92.0 \%$ and $90.7 \%$; at 10 years, these were $84.1 \%$ and $89.4 \%$ ( $\log \operatorname{rank} P=.90)$. Unadjusted 5 -year freedom from the combined outcome of death or repeat revascularization was $90.1 \%$ and $88.6 \% ; 10$-year freedoms were $77.1 \%$ and $79.7 \%(\log$ rank $P=.49)$. After adjustment, an RITA-right coronary system anastomosis did not increase the hazard of mortality (HR, 1.26; 95\% CI, 0.66-2.43; $P=.48$ ); repeat revascularization (HR, $1.01 ; 95 \% \mathrm{CI}, 0.55-1.87 ; P=.96)$, or the composite outcome (HR, 1.14; 95\% CI, 0.72-1.79; $P=.58$ ) compared with an RITA-left coronary system anastomosis.

\section{DISCUSSION}

There is clear evidence amassed over decades supporting the use of the LITA to the LAD in CABG surgery. ${ }^{1-3}$ Specifically, ITA use has been shown to improve graft patency, decrease recurrent myocardial infarction, and prolong overall survival. The use of the biologically similar RITA as a second bypass conduit was a natural extension of these data. Most studies suggest survival benefits with BITA use, ${ }^{4-10,12,28-30}$ and in light of these accumulating data, the most recent Society of Thoracic 


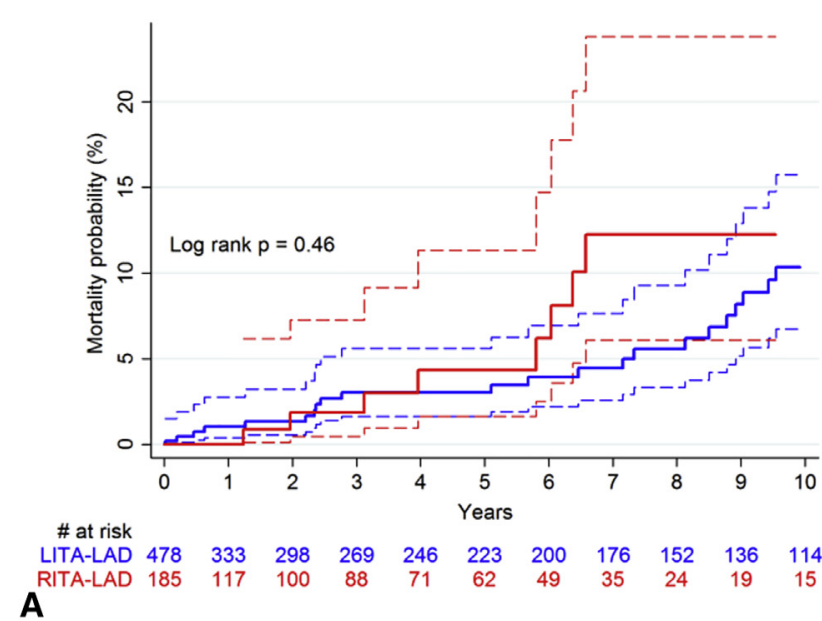

A

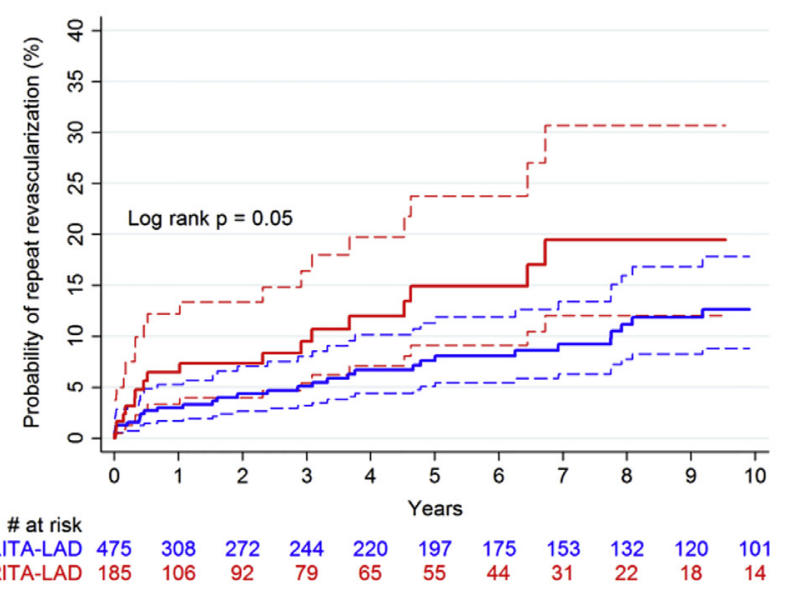

B

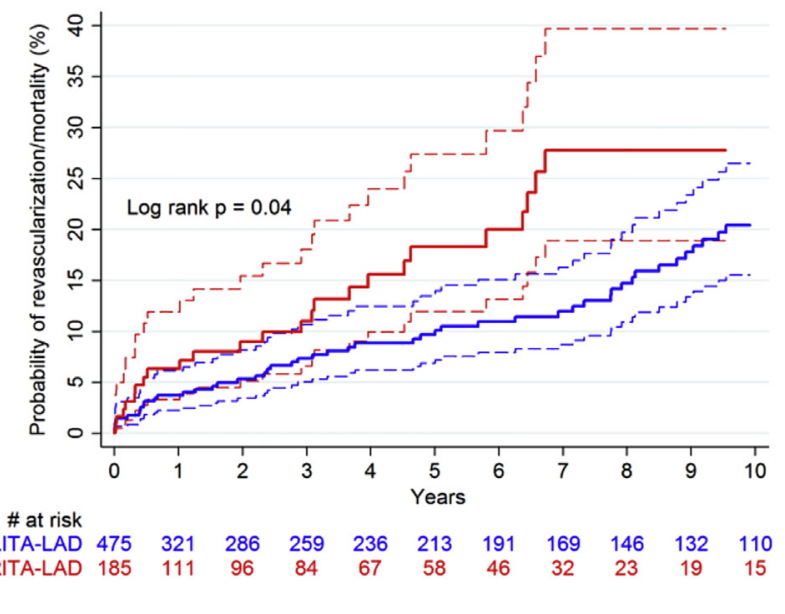

FIGURE 2. Kaplan-Meier curves comparing all patients with a left internal thoracic artery-left anterior descending artery anastomosis to all patients with a right internal thoracic artery-left anterior descending artery anastomosis for the outcomes of (A) Death; (B) Repeat revascularization; and (C) Combined death or repeat revascularization. LITA, Left internal thoracic artery; $L A D$, left anterior descending artery; RITA, right internal thoracic artery.

Surgeons Clinical Practice Guidelines on Arterial Conduits for Coronary Artery Bypass Grafting recommend that a second skeletonized ITA graft be used in patients not at excessive risk of sternal complications. ${ }^{31}$ However, data have not provided unequivocal support for BITA grafting in all patient populations. ${ }^{13,16-19,21,32,33}$

One possible explanation for this discrepancy may be that not all BITA configurations are equally effective. Indeed, some configurations are more technically challenging to perform than others. In the case of in situ conduits, geometric factors like graft tension or torsion could mitigate any advantage gained in using the RITA. The use of composite grafting allows bypass of the left-sided vessels with ITAs without the need for a proximal anastomosis to the aorta and with less concern regarding length compared with in situ ITAs. However, this maneuver is technically more challenging than in situ techniques. If the LITA is used as inflow, the technique potentially puts the most important graft at risk. If a saphenous vein graft is used as inflow, long-term patency may be threatened by proximal vein graft disease.

There is a relative paucity of literature specifically examining the comparative outcomes of various configurations of BITA use. Historically, after the LITA-LAD anastomosis is performed, the RITA was used in situ to bypass the next most important lesion. ${ }^{34}$ Others have advocated the use of the RITA in situ to bypass the right coronary artery system. Two large series have shown no difference in long-term outcomes whether the RITA was anastomosed to the right or left coronary circulation. ${ }^{11,35,36}$ Our findings regarding a lack of differences on outcomes parallel the series of Kurlansky and colleagues ${ }^{5}$ and Sabik and colleagues ${ }^{35}$; moreover, we similarly found that the RITA was anastomosed to the left coronary circulation more commonly than to the right (particularly in more recent years). Another technique that facilitates the use of in situ grafts is the use of the RITA to bypass the LAD and the LITA to another left sided target. As with our second pairwise analysis, this approach has previously been shown to be safe and effective. ${ }^{32}$

In our analysis, we did not demonstrate any independent effect of graft configuration on survival or freedom from repeat revascularization. Our adjusted analysis was designed as 3 pairwise comparisons of clinically relevant options. In the first analysis (LL/RL vs RL/LL), we found no difference for in situ BITA graft configurations when the 2 distal targets are the LAD and another vessel of the left coronary system. In the second subgroup analysis, we compared patients with an LITA to LAD anastomosis to those with an RITA to LAD anastomosis. In this subgroup analysis, we found no difference in terms of survival or the need for repeat revascularization between the 2 groups. These findings are consistent with those of a number of other investigators. ${ }^{11,32,35,37}$

Finally, our third subgroup analysis compared RITA grafts anastomosed to the left or right coronary systems among all patients with a LITA-LAD anastomosis. Several 
studies have suggested that RITA grafting to the right coronary artery system may be less beneficial than to the left coronary system. ${ }^{25-27}$ We found no differences in the need for repeat revascularization or overall mortality whether the RITA was anastomosed to the left or right coronary systems, although we were unable to control for the degree of right coronary stenosis preoperatively. Moreover, although unadjusted analysis suggested that free RITA harvesting and use as a Y graft was associated with a need for repeat revascularization, this finding was also not significant after risk adjustment. We noted that a quarter of patients in the RITA-left system group had the RITA graft constructed as a Y graft. These findings comport with a recent study documenting no differences in 15-year survival between 2 propensity-matched groups of patients who underwent BITA grafting with in situ versus free RITA grafts. ${ }^{38}$ Similarly, this study found that BITA grafting involving the use of the RITA as a free Y graft did not adversely affect 15 -year survival over in situ BITA grafting. It is important to note that the mean follow-up for the composite grafting group is significantly shorter than that of the other groups. As such, comparisons involving this group in particular are limited in power.

It is interesting to note that the incidence of mediastinitis was reasonable in this series of 762 patients having undergone BITA harvesting. Although our aggregate incidence of diabetes in this series was $19.7 \%$, mediastinitis occurred in only 5 patients, for a rate of $0.7 \%$. This is comparable to a recent series of patients undergoing CABG with both single ITA and BITA harvesting that reported a mediastinitis rate of $0.6 \% .^{39}$ Our overall skeletonization rate was only about $25 \%$, with significant rate differences among the 4 groups. Though some investigators have found that RITA skeletonization is associated with a lower rate of surgical site infection, ${ }^{40,41}$ our data are in keeping with others finding that pedicled BITA harvesting does not increase the occurrence of infectious complications. ${ }^{42}$ However, this is speculative, because this study was likely underpowered to examine that outcome.

Our study has several important limitations. By design we sought to examine different configurations of BITA use. This limited our sample size to 4 relatively small groups of patients. This combined with relatively low event rates limited statistical power. For example, given the group sizes in the comparison of patients who received both ITAs to the left coronary circulation, the minimum detectable HR for the composite outcome under lenient conditions (eg, $80 \%$ power) would be 1.52 , below our HR of 1.01 . For the comparison of LITA-LAD versus RITA-LAD patients, the minimum detectable HR would be 1.35 , compared with our HR of 1.00; and for the comparison of RITA to left or right coronary systems, the minimum detectable HR would be 1.31 , compared with our finding of 1.14 .
We were unable to pursue further contact with patients and/or their physicians due to resource constraints-a common problem in a study with such outcomes as ours. Moreover, the limited follow-up time observed for included patients limits our ability to draw definitive conclusions about bilateral arterial graft configurations, particularly because many have shown that the benefit of arterial grafting strategies accrue over long time periods. Additionally, this study is subject to all limitations inherent to a retrospective study design. Although we did adjust for operative year in calculating the propensity score, our results may still be vulnerable to temporal trends, technical nuances, and surgeon-specific practices that we cannot effectively capture. Moreover, weighting of our regression models with the propensity score as a covariate may induce bias. ${ }^{43}$ There is the possibility that some events were not captured in our chart review and follow-up resulting in information bias that may affect the results. Additionally, repeat revascularization procedures that did not occur within our health system may not have been captured. We also did not have reliable access to angiographic follow-up for use in assessing graft patency.

\section{CONCLUSIONS}

We found no significant difference in terms of long-term survival or freedom from repeat revascularization between different configurations of BITA use. We have confirmed that excellent short- and long-term results can be achieved with BITA use. Based on these findings the selection of the ideal BITA configuration should be based on individual patient technical factors. In general, the technically simplest operation should be selected because more complex procedures offer no additional benefit.

\section{Conflict of Interest Statement}

Authors have nothing to disclose with regard to commercial support.

\section{References}

1. Cameron AA, Green GE, Brogno DA, Thornton J. Internal thoracic artery grafts: 20-year clinical follow-up. J Am Coll Cardiol. 1995;25:188-92.

2. Loop FD, Lytle BW, Cosgrove DM, Stewart RW, Goormastic M, Williams GW, et al. Influence of the internal-mammary-artery graft on 10-year survival and other cardiac events. N Engl J Med. 1986;314:1-6.

3. Lytle BW, Loop FD, Cosgrove DM, Ratliff NB, Easley K, Taylor PC. Long-term ( 5 to 12 years) serial studies of internal mammary artery and saphenous vein coronary bypass grafts. J Thorac Cardiovasc Surg. 1985;89:248-58.

4. Glineur D, D'Hoore W, Price J, Dormeus S, de Kerchove L, Dion R, et al. Survival benefit of multiple arterial grafting in a 25-year single-institutional experience: the importance of the third arterial graft. Eur J Cardiothorac Surg. 2012;42:284-90; discussion 290-1.

5. Kurlansky PA, Traad EA, Dorman MJ, Galbut DL, Zucker M, Ebra G. Thirty-year follow-up defines survival benefit for second internal mammary artery in propensity-matched groups. Ann Thorac Surg. 2010;90:101-8.

6. Endo M, Nishida H, Tomizawa Y, Kasanuki H. Benefit of bilateral over single internal mammary artery grafts for multiple coronary artery bypass grafting. Circulation. 2001;104:2164-70.

7. Dorman MJ, Kurlansky PA, Traad EA, Galbut DL, Zucker M, Ebra G. Bilateral internal mammary artery grafting enhances survival in diabetic 
patients: a 30-year follow-up of propensity score-matched cohorts. Circulation. 2012;126:2935-42.

8. Kurlansky PA, Traad EA, Dorman MJ, Galbut DL, Zucker M, Ebra G. Bilateral internal mammary artery grafting reverses the negative influence of gender on outcomes of coronary artery bypass grafting surgery. Eur J Cardiothorac Surg. 2013:44:54-63.

9. Kinoshita T, Asai T, Suzuki T, Kuroyanagi S, Hosoba S, Takashima N. Off-pump bilateral skeletonized internal thoracic artery grafting in elderly patients. Ann Thorac Surg. 2012;93:531-6.

10. Medalion B, Mohr R, Frid O, Uretzky G, Nesher N, Paz Y, et al. Should bilateral internal thoracic artery grafting be used in elderly patients undergoing coronary artery bypass grafting? Circulation. 2013;127:2186-93.

11. Kurlansky PA, Traad EA, Dorman MJ, Galbut DL, Zucker M, Ebra G. Location of the second internal mammary artery graft does not influence outcome of coronary artery bypass grafting. Ann Thorac Surg. 2011;91:1378-83; discussion 1383-4.

12. Bonacchi M, Battaglia F, Prifti E, Leacche M, Nathan NS, Sani G, et al. Early and late outcome of skeletonised bilateral internal mammary arteries anastomosed to the left coronary system. Heart. 2005;91:195-202.

13. Kieser TM, Lewin AM, Graham MM, Martin BJ, Galbraith PD, Rabi DM, et al. Outcomes associated with bilateral internal thoracic artery grafting: the importance of age. Ann Thorac Surg. 2011;92:1269-75; discussion 1275-6.

14. Tabata M, Grab JD, Khalpey Z, Edwards FH, O’Brien SM, Cohn LH, et al. Prevalence and variability of internal mammary artery graft use in contemporary multivessel coronary artery bypass graft surgery: analysis of the Society of Thoracic Surgeons National Cardiac Database. Circulation. 2009;120:935-40.

15. Kappetein AP, Dawkins KD, Mohr FW, Morice MC, Mack MJ, Russell ME, et al. Current percutaneous coronary intervention and coronary artery bypass grafting practices for three-vessel and left main coronary artery disease. Insights from the SYNTAX run-in phase. Eur J Cardiothorac Surg. 2006;29:486-91.

16. Agrifoglio M, Trezzi M, Barili F, Dainese L, Cheema FH, Topkara VK, et al. Double vs single internal thoracic artery harvesting in diabetic patients: role in perioperative infection rate. J Cardiothorac Surg. 2008;3:35.

17. Baradi A, Milsom PF, Merry AF, Ferguson LR. Are two internal thoracic artery grafts as safe as one? Experience from Green Lane Hospital. N Z Med J. 2012; 125:36-41.

18. Dalen M, Ivert T, Holzmann MJ, Sartipy U. Bilateral versus single internal mammary coronary artery bypass grafting in Sweden from 1997-2008. PLoS One. 2014;9:e86929.

19. Joo HC, Youn YN, Yi G, Chang BC, Yoo KJ. Off-pump bilateral internal thoracic artery grafting in right internal thoracic artery to right coronary system. Ann Thorac Surg. 2012;94:717-24.

20. Nakano J, Okabayashi H, Hanyu M, Soga Y, Nomoto T, Arai Y, et al. Risk factors for wound infection after off-pump coronary artery bypass grafting: should bilateral internal thoracic arteries be harvested in patients with diabetes? J Thorac Cardiovasc Surg. 2008;135:540-5.

21. Saito A, Miyata H, Motomura N, Ono M, Takamoto S. Propensity-matched analysis of bilateral internal mammary artery vs single internal mammary artery in 7702 cases of isolated coronary artery bypass grafting. Eur J Cardiothorac Surg. 2013;44:711-7.

22. Nakajima H, Kobayashi J, Tagusari O, Bando K, Niwaya K, Kitamura S. Competitive flow in arterial composite grafts and effect of graft arrangement in Off-Pump coronary revascularization. Ann Thorac Surg. 2004;78:481-6.

23. Nakajima H, Kobayashi J, Toda K, Fujita T, Shimahara Y, Kasahara Y, et al. A 10-year angiographic follow-up of competitive flow in sequential and composite arterial grafts. Eur J Cardiothorac Surg. 2011;40:399-404.

24. Buxton BF, Ruengsakulrach P, Fuller J, Rosalion A, Reid CM, Tatoulis J. The right internal thoracic artery graft-benefits of grafting the left coronary system and native vessels with a high grade stenosis. Eur J Cardiothorac Surg. 2000; 18:255-61.

25. Carrel T, Horber P, Turina MI. Operation for two-vessel coronary artery disease: midterm results of bilateral ITA grafting versus unilateral ITA and saphenous vein grafting. Ann Thorac Surg. 1996;62:1289-94.
26. Naunheim KS, Barner HB, Fiore AC. 1990: Results of internal thoracic artery grafting over 15 years: single versus double grafts. 1992 update. Ann Thorac Surg. 1992;53:716-8

27. Schmidt SE, Jones JW, Thornby JI, Miller CC III, Beall AC Jr. Improved survival with multiple left-sided bilateral internal thoracic artery grafts. Ann Thorac Surg. 1997:64:9-14; discussion 15.

28. Weiss AJ, Zhao S, Tian DH, Taggart DP, Yan TD. A meta-analysis comparing bilateral internal mammary artery with left internal mammary artery for coronary artery bypass grafting. Ann Cardiothorac Surg. 2013;2:390-400.

29. Mohammadi S, Dagenais F, Doyle D, Mathieu P, Baillot R, Charbonneau E, et al. Age cut-off for the loss of benefit from bilateral internal thoracic artery grafting. Eur J Cardiothorac Surg. 2008;33:977-82.

30. Raza S, Sabik JF III, Masabni K, Ainkaran P, Lytle BW, Blackstone EH Surgical revascularization techniques that minimize surgical risk and maximize late survival after coronary artery bypass grafting in patients with diabetes mellitus. J Thorac Cardiovasc Surg. 2014;148:1257-64; discussion 1264-6.

31. Aldea GS, Bakaeen FG, Pal J, Fremes S, Head SJ, Sabik J, et al. The Society of Thoracic Surgeons Clinical Practice Guidelines on Arterial Conduits for Coronary Artery Bypass Grafting. Ann Thorac Surg. 2016;101:801-9.

32. Raja SG, Benedetto U, Husain M, Soliman R, De Robertis F, Amrani M. Does grafting of the left anterior descending artery with the in situ right internal thoracic artery have an impact on late outcomes in the context of bilateral internal thoracic artery usage? J Thorac Cardiovasc Surg. 2014;148:1275-81.

33. Taggart DP, Altman DG, Gray AM, Lees B, Nugara F, Yu LM, et al. Randomized trial to compare bilateral vs. single internal mammary coronary artery bypass grafting: 1-year results of the Arterial Revascularisation Trial (ART). Eur Heart J. 2010;31:2470-81.

34. Cooley DA. Coronary bypass grafting with bilateral internal thoracic arteries and the right gastroepiploic artery. Circulation. 1998;97:2384-5.

35. Sabik JF III, Stockins A, Nowicki ER, Blackstone EH, Houghtaling PL, Lytle BW, et al. Does location of the second internal thoracic artery graft influence outcome of coronary artery bypass grafting? Circulation. 2008; 118(Suppl):S210-5.

36. Toker ME, Omeroglu SN, Kirali K, Balkanay M, Yakut C. Using the bilatera internal mammary artery in the left or right coronary artery system: 5-year comparison of operation techniques and angiographic results. Heart Surg Forum. 2005;8:E462-7.

37. Tatoulis J, Buxton BF, Fuller JA. The right internal thoracic artery: the forgotten conduit-5,766 patients and 991 angiograms. Ann Thorac Surg. 2011;92:9-15 discussion 15-7.

38. Shi WY, Hayward PA, Tatoulis J, Rosalion A, Newcomb AE, Fuller JA, et al. Are all forms of total arterial revascularization equal? A comparison of single versus bilateral internal thoracic artery grafting strategies. J Thorac Cardiovasc Surg. 2015;150:1526-34.e3.

39. Risnes I, Abdelnoor M, Almdahl SM, Svennevig JL. Mediastinitis after coronary artery bypass grafting risk factors and long-term survival. Ann Thorac Surg. 2010;89:1502-9.

40. Deo SV, Shah IK, Dunlay SM, Erwin PJ, Locker C, Altarabsheh SE, et al. Bilateral internal thoracic artery harvest and deep sternal wound infection in diabetic patients. Ann Thorac Surg. 2013;95:862-9.

41. Milani R, Brofman PR, Guimaraes M, Barboza L, Tchaick RM, Meister Filho H, et al. Double skeletonized internal thoracic artery vs. double conventional internal thoracic artery in diabetic patients submitted to OPCAB. Rev Bras Cir Cardiovasc. 2008;23:351-7.

42. Choo SJ, Lee SK, Chung SW, Kim JW, Sung SC, Kim YD, et al. Does bilateral pedicle internal thoracic artery harvest increase the risk of mediastinitis? Yonsei Med J. 2009;50:78-82.

43. Hade EM, Lu B. Bias associated with using the estimated propensity score as a regression covariate. Stat Med. 2014;33:74-87.

Key Words: coronary artery disease, coronary artery bypass, internal thoracic artery, outcomes 